\author{
Marquette University \\ e-Publications@Marquette
}

\title{
Improved Reliability of Stormwater Detention Basin Performance Through Water Quality Data-informed Real-time Control
}

\author{
Sazzad Sharior \\ Marquette University \\ Walter M. McDonald \\ Marquette University, walter.mcdonald@marquette.edu \\ Anthony J. Parolari \\ Marquette University, anthony.parolari@marquette.edu
}

Follow this and additional works at: https://epublications.marquette.edu/civengin_fac

Part of the Civil Engineering Commons

\section{Recommended Citation}

Sharior, Sazzad; McDonald, Walter M.; and Parolari, Anthony J., "Improved Reliability of Stormwater Detention Basin Performance Through Water Quality Data-informed Real-time Control" (2019). Civil and Environmental Engineering Faculty Research and Publications. 248.

https://epublications.marquette.edu/civengin_fac/248 
Marquette University

e-Publications@Marquette

\section{Civil, Construction and Environmental Engineering Faculty Research and Publications/College of Engineering}

This paper is NOT THE PUBLISHED VERSION; but the author's final, peer-reviewed manuscript. The published version may be accessed by following the link in the citation below.

Journal of Hydrology, Vol. 573 (June 2019): 422-431. DOI. This article is (C) Elsevier and permission has been granted for this version to appear in e-Publications@Marquette. Elsevier does not grant permission for this article to be further copied/distributed or hosted elsewhere without the express permission from Elsevier.

\section{Improved Reliability of Stormwater Detention Basin Performance Through Water Quality Data-informed Real-time Control}

\section{Sazzad Sharior}

Department of Civil, Construction, and Environmental Engineering, Marquette University, Milwaukee, WI

Walter McDonald Department of Civil, Construction, and Environmental Engineering, Marquette University, Milwaukee, WI

Anthony J. Parolari

Department of Civil, Construction, and Environmental Engineering, Marquette University, Milwaukee, WI

\section{Abstract}

Stormwater detentions basins are designed to capture stormwater to reduce and delay peak flows and to improve water quality. A novel technology proposed to improve basin performance is real-time, active control of the basin outflow, in so-called "smart" stormwater systems. Existing studies 
demonstrate the performance of active controls that respond in real-time to basin water level, detention time, and rainfall forecast for one or a small number of rainfall events. We hypothesize that the performance of these active controls can be improved by incorporating real-time water quality data into the control algorithm. In addition, we hypothesize that active control performance depends on hydrologic variability, specifically the frequency and intensity of runoff inputs. In this paper, we test these hypotheses using a numerical modeling framework for systems-level reliability analysis of active and passive stormwater basin outflow control using a Monte Carlo method. The analysis is performed using the urban hydrology model EPA-SWMM driven by stochastic rainfall time-series generated from the Modified Bartlett-Lewis Rectangular Pulses Model. Water quality-informed real-time active control algorithms are developed, tested, and shown to display an improvement over traditional, passive (no control) systems and other storage-based active controls for water and pollutant capture. Seasonal and duration curve analysis showed that water level- and water quality-informed control performance varied for different storm return periods and this variability could partly be attributed to the fraction of time the valve is closed. In addition, control performance was sensitive to rainfall variability, generally decreasing as storms become less frequent and more intense. Therefore, control system performance may depend on seasonal and longer time-scale variability in climate and rainfall-runoff processes. We anticipate this study to be a starting point to incorporate theories of reliability to assess detention basin and conveyance network performance under more complex real-time control algorithms and failure modes.

\section{Keywords}

Stormwater management, Urban runoff, Real-time control, Water quality

\section{Introduction}

Urbanization and climate change are creating new challenges to stormwater management and the protection of urban stream ecosystems. Urbanization results in flashier hydrographs, increased threat of flooding, and higher pollutant concentrations in stormwater runoff (Leopold, 1968) - all characteristics of the "urban stream syndrome" (Meyer et al., 2005, Walsh et al., 2005) At the same time, recent and forthcoming changes in rainfall frequency and intensity (Alexander et al., 2006, Kunkel et al., 2013) are also anticipated to impact stormwater runoff and water quality (Miller and Hutchins, 2017). In the Midwest United States, for example, urban stormwater system adaptation to increased frequency and intensity of severe rainfall is anticipated to cost more than $\$ 500$ million per year (Angel. et al., 2018). Current stormwater management practices, such as detention/retention basins, are poorly equipped to adapt to these consequences of continuously changing climate and land use (Mullapudi et al., 2017). Therefore, novel stormwater management strategies are needed to improve the resilience and adaptability of urban stormwater infrastructure.

One strategy to adapt stormwater infrastructure to changing rainfall-runoff conditions, is real-time, active control of stormwater detention basin outflows. Active control based on system flow and water level monitoring has been shown to reduce wet weather pollutant discharge at the scale of individual stormwater facilities (Jacopin et al., 2001) and collection systems (Colas et al., 2004, Pleau et al., 2005, Wong and Kerkez, 2018). Further, active controls based on monitoring of rainfall forecast, water level, outflow, and/or detention time have been shown to improve pollutant removal efficiency $40-90 \%$ and 
to reduce outflows (Gaborit et al., 2013, Muschalla et al., 2014, Gaborit et al., 2016). In addition to improving the performance of stormwater ponds with passive outflow control, active controls can be employed to reduce the engineered watershed storage volume by up to $50 \%$ (Wong and Kerkez, 2018). While these studies provide strong evidence for the water quantity and quality benefits of active outflow control for a small number of storms, active control performance has yet to be analyzed for the full range of rainfall variability over the lifetime of stormwater infrastructure (e.g., 10-30 years).

A major challenge to stormwater management is to make effective predictions under large uncertainty driven by variability in hydrologic processes. While stormwater management infrastructure, like stormwater ponds, are typically designed to manage volume and peak flow for a small number of design storms, they operate under a wide range of inflow conditions determined by the timing and frequency of rainfall-runoff events. Stormwater infrastructure performance can be evaluated for a large number of inflow conditions using models that combine a stochastic description of the rainfall variability with the watershed water and pollutant mass balance equations (Chen and Adams, 2006, Daly et al., 2012, Parolari et al., 2018, Wang and Guo, 2019). These stochastic-dynamic modeling approaches provide an estimate of the flow and load duration curves, which can be useful for understanding stormwater infrastructure performance for average and extreme events. This approach was previously applied to a stormwater control pond with a water level-driven on/off control (Parolari et al., 2018). Active outflow control increased the probability of high outflows and decreased the probability of low outflows, demonstrating that the performance of active control depends on rainfall return period. For this simple control, it was shown that real-time control rules can be adjusted over time to adapt stormwater pond performance to changes in climate and land use that alter watershed rainfall-runoff dynamics (Parolari et al., 2018). Therefore, the influence of rainfall variability on active control performance is an important consideration in the analysis and design of stormwater infrastructure with active control.

While water level provides a direct observation of the current basin storage and rainfall forecasts can anticipate the need for increased storage, the detention time following a runoff event only provides an indirect measurement of water quality. Therefore, the performance of actively controlled stormwater infrastructure may be improved by incorporating water quality measurements into control strategies. Recent advances in water quality monitoring technology (Rode et al., 2016) have made it possible to measure stormwater runoff water quality in real time. In addition, water quality-informed real-time control has been used for treatment process control in wastewater treatment plants. Real-time controls based on turbidity were shown to reduce pollutant loads to receiving waters by $10-40 \%$ (Lacour et al., 2011, Lacour and Schütze, 2011, Hoppe et al., 2011, Tik et al., 2015). However, water quality-informed real-time controls have yet to be analyzed or developed for stormwater applications, which are subject to relatively large perturbations due to hydrologic variability.

In this paper, we address the two research gaps addressed above by evaluating novel real-time controls of stormwater detention ponds informed by water quality measurements using a stochastic Monte Carlo method. Building on previous control algorithms based on water storage or flux data, we develop control rules that utilize continuous water quality measurements. The control algorithms are implemented in the EPA-SWMM model developed for an urban watershed that drains to an actively 
controlled detention pond in Milwaukee, Wisconsin. The system reliability with respect to water quantity and quality criteria is compared across a range of control strategies and hydrologic variability.

\section{Methods}

\subsection{Catchment system model}

An urbanized catchment that discharges into a stormwater detention pond can be conceptualized as a four-dimensional dynamical system that accounts for the coupling between the catchment water balance, catchment pollutant storage, pond water storage, and pond pollutant concentration. Mass balance equations for each of these components are defined below and the system is illustrated in Fig. 1.


Fig. 1. Catchment system conceptual model with traditional and proposed real-time active system controls. The system state variables are soil moisture, $s$, detention pond water level, $h$, catchment pollutant mass, $m$, and detention pond pollutant concentration, $C$. The hydrologic fluxes are: precipitation, $R$, evapotranspiration, $E T$, infiltration, $L$, catchment runoff, $Q_{r o}$, pond discharge, $Q_{\text {out }}$, pond emergency overflow, , and pond seepage to groundwater, $G$. The pollutant fluxes are: catchment buildup, $B$, catchment washoff, $W$, detention pond settling, $S_{d}$, and detention pond outflow, $Q_{\text {out }} C$. Traditional detention pond outflow control is implemented through a feedback between $h$ and $Q_{\text {out }}$, whereas this paper evaluates a control feedback between $C$ and $Q_{\text {out }}$.

The catchment water balance can be written as

(1) $\frac{d s(t)}{d t}=R(t)-E T[s(t)]-L[s(t)]-Q_{r o}[s(t)]$

where $s$ is the depression storage, $R$ is rainfall, ET is evapotranspiration, $L$ is infiltration, and $Q_{r o}$ is catchment runoff. Similarly, a water balance equation for the pond can be written as,

(2) $\frac{d h(t)}{d t}=Q_{\text {ro }}[s(t)]-Q_{\text {out }}[h(t) ; t]-Q_{o}[h(t)]-G[h(t)]$

which is driven by the catchment rainfall-runoff process through $Q_{r o}$. In Eq. (2), $h$ is the pond water level, $Q_{\text {out }}[h(t) ; t]$ is the state and time dependent pond outflow, $Q_{o}$ is the emergency overflow, and $G$ is seepage to groundwater. 
The catchment pollutant mass balance can be conceptualized as the difference between buildup and washoff processes (Alley, 1981). The catchment pollutant mass balance equation can be written as,

(3) $\frac{d m(t)}{d t}=B-W\left[Q_{r o}[s(t)], m(t)\right]$

where $m(t)$ is the mobile pollutant mass stored on catchment surfaces, $B$ is the constant pollutant buildup rate, and $W\left(Q_{\text {ro }}[s(t)]\right)$ is the pollutant washoff rate. Finally, the mass balance for the pollutant mass stored within the pond can be written as,

(4) $\frac{d[h(t) C(t)]}{d t}=W\left[Q_{r o}[s(t)], m(t)\right]-Q_{\text {out }}[h(t) ; t] C(t)-S_{d}[h(t), C(t)]$

where $C(t)$ is the pollutant concentration in the pond water and $S_{d}[h(t), C(t)]$ is the pollutant removal rate.

\subsection{EPA-SWMM}

We used the U.S. EPA Stormwater Management Model (EPA-SWMM) to parameterize the catchment system model described in Eqs. (1), (2), (3), (4) (Rossman, 2015, https://www.epa.gov/waterresearch/storm-water-management-model-swmm). The model assumptions used in this study are summarized here, whereas we refer the reader to the EPA-SWMM model documentation for a detailed model description. The catchment water balance is modeled as a nonlinear reservoir with a maximum depression storage and modified Green-Ampt infiltration capacity that must be exceeded before runoff is initiated. Evapotranspiration is assumed to be negligible relative to the other water fluxes for urbanized catchments with a high impervious surface cover. The water balance is forced with hourly rainfall (see Section 2.4 below). The pond water balance is modeled according to Eq. (4), with a Vnotch weir (passive) or orifice (active) outflow and groundwater seepage modeled using the GreenAmpt method. The catchment pollutant buildup, $B$, is assumed constant and washoff is parameterized using the exponential washoff model, $W=K_{w} Q_{r o}^{N_{w}} m$, where $K_{w}$ and $N_{w}$ are calibrated coefficients. Total suspended solids (TSS) is assumed as the pollutant of interest. The detention pond is assumed to behave as a continuously stirred tank reactor. The removal mechanism for TSS is modeled as first-order decay which depends on the settling velocity of the suspended solids. Model input files that document all model assumptions and parameters can be obtained at https://github.com/sazzadsharior/Reliability_SWMM.

\subsection{Control rules}

This section describes the four control rules evaluated in this study: no control, detention time control, on/off control, and TSS control. The no control (baseline) scenario is defined as passive control with the valve open permanently. The detention time controller closes the valve to store the storm inflow in the pond for a specified detention time, $t_{d}$, following an inflow event (Middleton and Barrett, 2008). The on/off controller maintains the outflow valve in the closed position until the pond water level reaches an upper bound of $h_{c}$, at which point the pond is fully discharged (Jacopin et al., 2001, Gaborit et al., 2013, Muschalla et al., 2014, Gaborit et al., 2016, Parolari et al., 2018). These two controls correspond to the traditional water level-driven control shown in Fig. 1. For the TSS controller, the valve is closed when the TSS concentration of the pond exceeds a threshold value, $C_{c}$, and otherwise the valve is open. This control corresponds to the proposed water quality-driven control in Fig. 1. The control 
schemes are summarized in Table 1 and example pond water level and pollutant concentration trajectories for each are illustrated in Fig. 2.

Table 1. Control rules implemented in this study.

\begin{tabular}{|l|l|}
\hline Type & Description \\
\hline Passive Control & Valve always open \\
\hline Detention Control & $\begin{array}{l}\text { If an event occurs, valve opening }=0 \% \\
\text { After the event, valve opening }=0 \% \text { for } t_{d} \\
\text { Else, valve opening }=100 \%\end{array}$ \\
\hline On/off Control & $\begin{array}{l}\text { If } h<h_{c} \text {, valve opening }=0 \% \\
\text { If } h \geq h_{c}, \text { valve opening }=100 \%\end{array}$ \\
\hline TSS Control & $\begin{array}{l}\text { If } C \geq C_{c}, \text { valve opening }=0 \% \\
\text { If } C<C_{c}, \text { valve opening }=100 \% .\end{array}$ \\
\hline
\end{tabular}
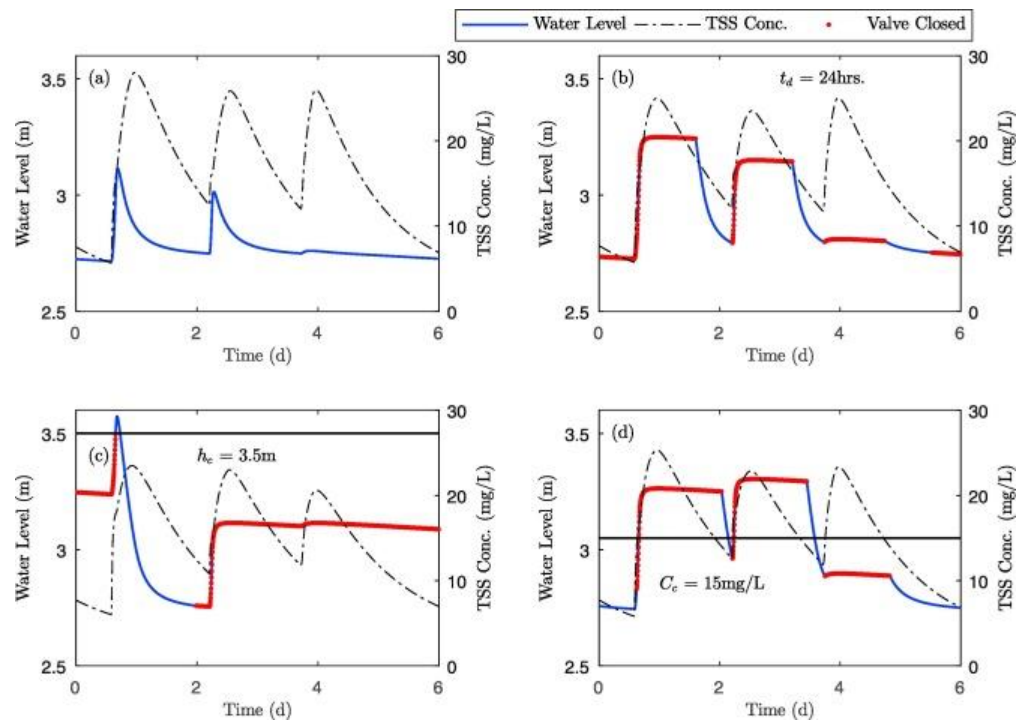

Fig. 2. Water level and TSS concentration dynamics of the pond for (a) passive control, (b) detention control, (c) on/off control and, (d) TSS control.

Real-time controls were implemented in PySWMM, a python wrapper around the SWMM computational engine. The source code is available here: https://github.com/sazzadsharior/Stormwater-Management-Model_forked_SS.

\subsection{Probabilistic rainfall description}

Stochastic rainfall models can be used to generate synthetic rainfall time series for investigating rainfall-sensitive hydrologic phenomena. Because we are interested in rare failure events, a rainfall model that can capture extreme events is necessary. Cluster based models like the Bartlett-Lewis Rectangular Pulses Model (BLRPM) can generate rainfall in a range of temporal scales preserving the extreme event statistics (Khaliq and Cunnane, 1996). In this study we use the Modified BLRPM (Rodriguez-Iturbe et al., 1988). 


\subsubsection{Modified Bartlett-Lewis Rectangular Pulses Model}

The modified BLRPM has six parameters, illustrated in Fig. 3 and described elsewhere (Islam et al., 1990, Khaliq and Cunnane, 1996, Smithers et al., 2002). Storm origins arrive as a Poisson process with rate parameter $\lambda$. Each storm origin is followed by a Poisson arrival of cell origins at a rate $\beta$, with one cell at the storm origin. The cell arrival process terminates with rate parameter $\gamma$. Each cell in a storm event is a rectangular pulse with exponentially distributed depth and width of $\mu_{x}$ and $\eta$, respectively. Each storm has $C$ number of cells. $C$ is geometrically distributed with a mean, $\mu_{c}=1+\kappa / \phi$. Here, $\kappa$ and $\phi$ are dimensionless parameters with $k=\beta / \eta$ and $\phi=\gamma / \eta$. The cell width parameter $\eta$ is modeled as a random variable described by a two-parameter gamma distribution, with parameters $\alpha$ and $v$. The BLRPM model structure and parameters are shown in Fig. 3.

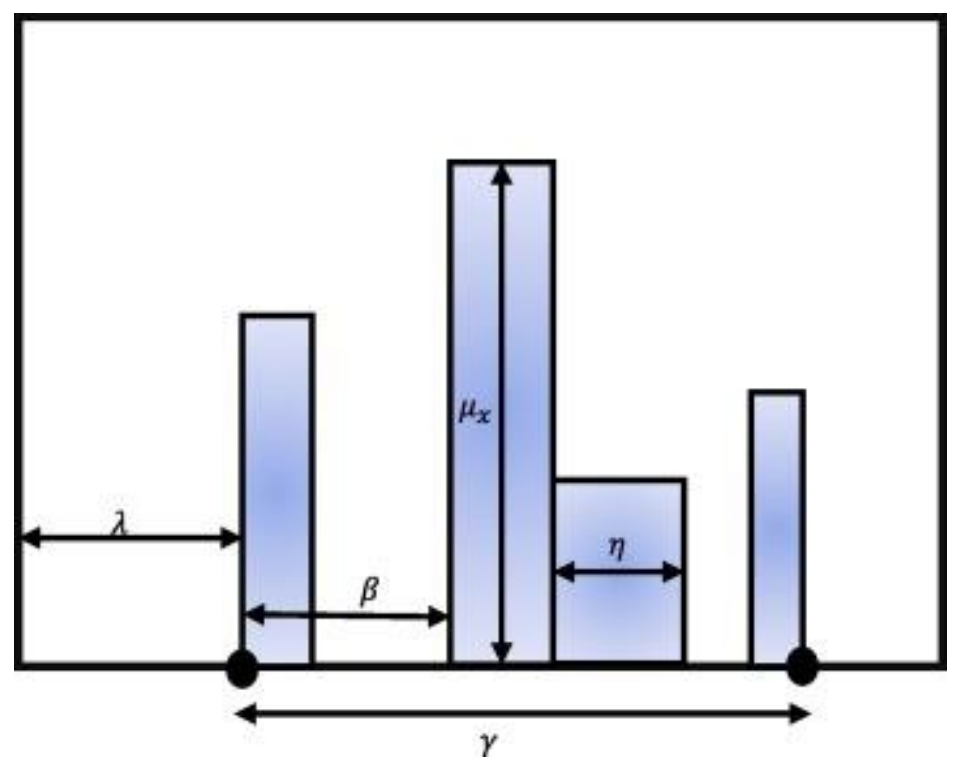

Fig. 3. Modified Bartlett-Lewis Rectangular Pulses Model schematic. The two black circles represent the storm arrival at the rate, $\lambda$, and termination of the storm event with rate parameter, $\gamma$. The blue rectangles show the rainfall cells. The width and height of rainfall cells are given by the cell duration, $\eta$, and cell intensity, $\mu_{x}$. Cells arrive at a rate, $\beta$, and each storm has a number of cells, $C$.

\subsubsection{Modified BLRPM parameter estimation and sampling}

Thirty years of hourly rainfall data (1983-2013) for the rainfall station located at General Mitchell Airport, Milwaukee, Wisconsin were obtained from NOAA Local Climatological Data (https://www.ncdc.noaa.gov/cdo-web/datatools/lcd). For each month, statistical properties were calculated, including the mean, variance, probability of zero rainfall, and autocorrelations at 1-, 2-, and 3-hour lags.

The six parameters, $\left(\lambda, \mu_{x}, \alpha, v, \kappa\right.$, and $\left.\phi\right)$ of the Modified BLRPM were estimated using the statistics calculated from the data. Statistics calculated from historical observations are equated with their theoretical expressions, which can be found in Rodriguez-Iturbe et al. (1987). Statistics used were 1hour mean, 1-hour and 24-hour variance, lag-1 autocorrelation, and 1-hour and 24-hour probability of zero rainfall (Rodriguez-Iturbe et al., 1987, Khaliq and Cunnane, 1996). The resulting equations are solved using an unconstrained nonlinear minimization scheme (Islam et al., 1990). 
In this paper, we focus on the spring and summer months that experience the most intense rainfall in Milwaukee: May, June, July, and August. Using the calibrated Modified BLRPM, 30-year rainfall realizations were sampled for each of the four months. The generated rainfall time series were used to force the EPA-SWMM model.

\subsection{System reliability by Monte Carlo methods}

This section of the paper discusses failure analysis by Monte Carlo Method and the limit state functions for basin performance failure. Two failure modes are defined for the detention basin: exceedance of either the basin overflow level or a maximum TSS concentration. Failure due to basin overflow depends on the available storage in the basin and the failure probability decreases with increasing available storage. Given a maximum pond water level, hmax, the limit state (failure criteria) function due to overflow is,

(5) $g_{h}[h(t)]=h_{\max }-h(t)$.

TSS failure occurs when the outflow TSS concentration exceeds the maximum TSS criterion, $C_{\max }$. Thus, this limit state function is,

(6) $g_{C}[C(t)]=C_{\max }-C(t)$.

The probability of failure due to either overflow or TSS failure can be computed by integrating the probability density functions (PDFs) of the state variables over the failure zone (Shinozuka, 1983, Schuëller and Stix, 1987). The probabilities of overflow and TSS failure can be written as,

$$
\begin{aligned}
& p_{f, h}=\int_{g_{h}(h) \leq 0} f_{h}(h) d h \\
& p_{f, C}=\int_{g_{C}(C) \leq 0} f_{C}(C) d C
\end{aligned}
$$

where $p_{f, h}$ and $p_{f, C}$ are the overflow and TSS probabilities of failure, $f_{h}(h)$ is the marginal PDF of pond water level, $h$, and $f_{C}(C)$ is the marginal PDF of pond outflow TSS concentration, $C$.

For this two-component series system, we consider a system failure to occur when either component fails (i.e., water level or concentration). Therefore, the system failure domain is the union of the component failure domains,

$$
\text { (8) } g(h, C) \leq 0=\bigcup_{i=1}^{n}\left[g_{i}(h, C) \leq 0\right]
$$

and the total system failure probability is then given by,

$$
\text { (9) } p_{f}=\int_{g(h, C) \leq 0} f_{h, C}(h, C) d h d C
$$

where, $f_{h, C}(h, C)$ is the joint PDF of water level and pollutant concentration. Time trajectories and PDFs of the pond state variables $h$ and $C$ were generated using the EPA-SWMM model, forced with stochastically generated rainfall, and the failure probabilities of Eqs. (7), (9) were calculated from these model results. 


\subsection{Case study}

The methodology described above was applied to analyze the performance of an actively controlled detention pond that captures stormwater runoff from the City of Milwaukee Department of Public Works Tow Lot in Milwaukee, Wisconsin. The drainage area is approximately 19.4 ha with $91 \%$ impervious cover and a mean slope of $0.65 \%$. The surface area of the detention pond is approximately $5760 \mathrm{~m}^{2}$ at a maximum depth of $6 \mathrm{~m}$ of which $4.8 \mathrm{~m}$ is permanent pool. The pond discharge is controlled by a valve that can be adjusted by an electric actuator.

The EPA SWMM model was calibrated using data collected at the Tow Lot detention pond. Water level was measured from August 22 to September 28, 2018 and turbidity data was measured from September 17 to September 28, 2018. Turbidity was measured at an elevation of approximately $2 \mathrm{~m}$ below the permanent pool elevation. In-situ turbidity measurements were used to calculate TSS concentrations using a regression developed with grab samples on multiple days.

\section{Results}

\subsection{Rainfall data and Modified BLRPM parameters}

A comparison of the observed and modeled rainfall statistics is shown in Fig. 4. There was good agreement between observed and modeled rainfall statistics. The variance of the 24-hour aggregated rainfall showed the largest deviation, with the model underpredicting the historical data by $28.7 \%$, $28.8 \%$, and $17.7 \%$ in June, July and August, respectively.
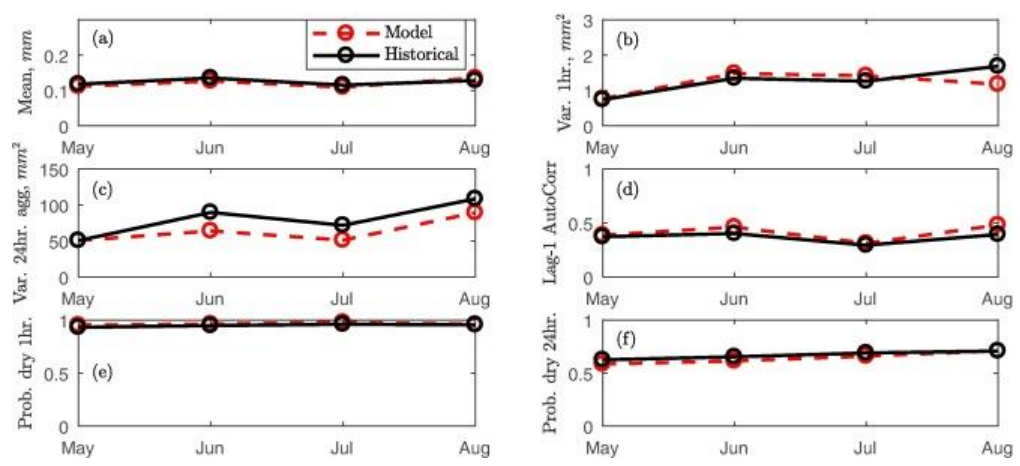

Fig. 4. Observed and modeled rainfall statistics using the Modified Barlett-Lewis Rectangular Pulses Model. (a) 1-hour rainfall mean, (b) 1-h rainfall variance, (c) 24-h rainfall variance (d) 1-h lag1 autocorrelation (e) 1-h probability of zero rainfall, (f) $24-\mathrm{h}$ probability of zero rainfall.

The Modified BLRPM parameters for each month are shown in Fig. 5. In general, the mean storm arrival frequency decreased and the mean cell depth increased throughout the summer, from May to August (Fig. 5a; b). May had the lowest and July had the greatest mean cell width, while June and August had similar intermediate values (Fig. 5c; d). Finally, in general, the mean number of cells increased throughout the summer, from May to August (Fig. 5e). Therefore, there was a strong contrast in rainfall statistical properties between months at this site. Early-season rainfall was characterized by frequent storms with low cell frequency, width, and depth. On the other hand, midto late-season rainfall was characterized by infrequent storms with high cell frequency, width, and depth. The influence of these rainfall characteristics on active control performance will be addressed below. 

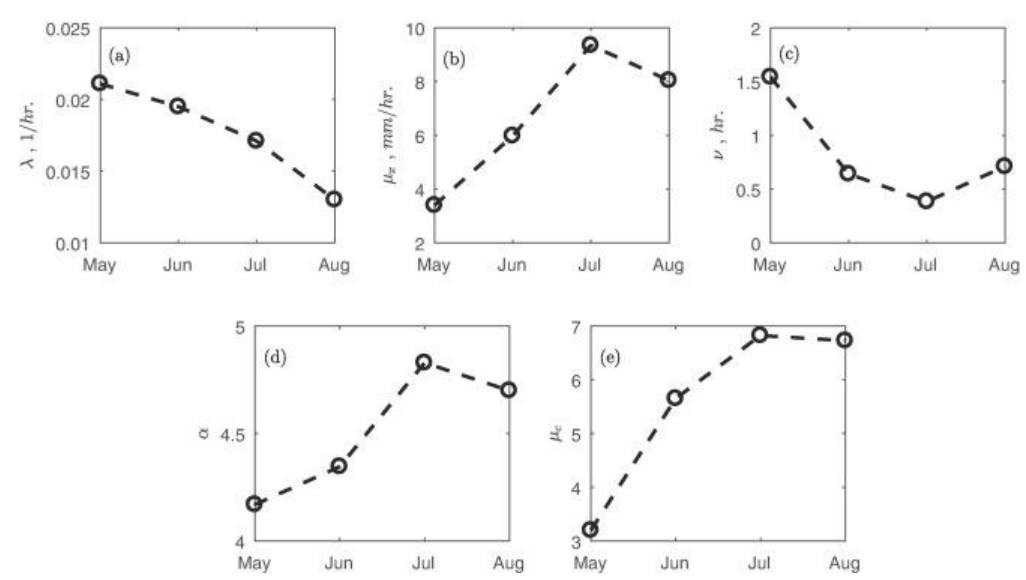

Fig. 5. Modified BLRPM parameters. (a) storm arrival rate, $\lambda\left(\mathrm{h}^{-1}\right)$, (b) mean cell depth, $\mu_{x},\left(\mathrm{~mm} \mathrm{~h}^{-1}\right)$, (c-d) Gamma distribution parameters for the cell width, $\eta, v\left(\mathrm{~h}^{-1}\right)$ and $\alpha$, (e) mean storm cell number, $\mu_{c}=1+\frac{\phi}{\kappa}$.

\subsection{SWMM model calibration}

SWMM model calibration results are shown in Fig. 6. The runoff model was calibrated by adjusting the impervious surface Manning's $n$ and depression storage. The calibration resulted in a coefficient of determination of 0.86 between the observed and modeled time series. The RMSE was 0.0343 and Nash-Sutcliffe efficiency coefficient was 0.8 . Fig. 6a shows the calibration result for the runoff model. The pollutant model was calibrated by adjusting the buildup rate constant, washoff exponent, and washoff coefficient. The calibration resulted in a coefficient of determination of 0.42 between the observed and modeled time series. The RMSE was 3.26 and Nash-Sutcliffe efficiency coefficient was -0.76 . Therefore, there was a substantial amount of variability in the measured TSS that the model was unable to capture. However, Fig. 6b shows that the model captures well the shape of the pollutograph.
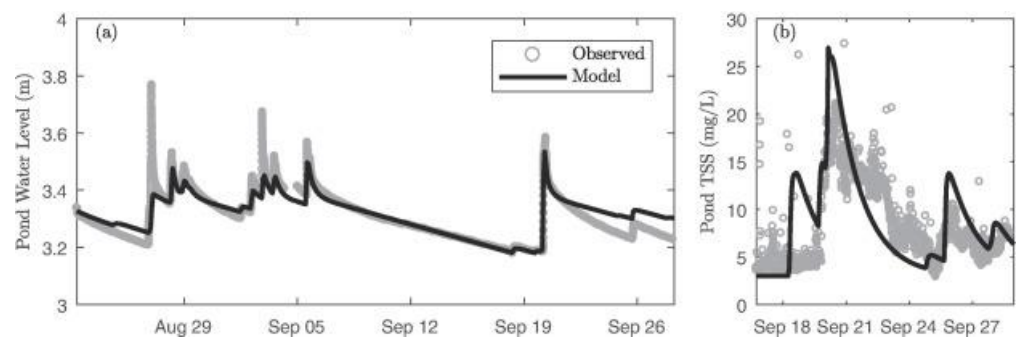

Fig. 6. SWMM model calibration. (a) runoff model calibrated from Aug. 22, 2018 to Sept. 28, 2018. (b) pollutant model calibrated from Sept. 17, 2018 to Sept. 28, 2018.

\subsection{Reliability analysis}

Bivariate histograms of the simulated pond outflow TSS concentration and water level for June are shown in Fig. 7. The red horizontal line indicates the TSS limit state function and the red vertical line indicates the overflow limit state function. Events that exceed these limit states individually, or together, indicate system failures. For June, passive control had the greatest number of points above the TSS concentration threshold (Fig. 7a) and, therefore, the TSS failure probability, $p_{f, c}$, was the largest for June. This trend is carried out through the other simulation months as well (Fig. 8b). For detention and on/off control, the TSS concentration threshold was exceeded less frequently (Fig. 7b; c) 
than the passive control and, therefore, $p_{f, C}$ was lower in June than the passive control (Fig. 8b). Finally, for the TSS control, the TSS concentration never exceeded the threshold (Fig. 7d). The TSS control was designed to limit the TSS concentration to below the threshold, resulting in zero $p_{f, C}$ for June and rest of the simulation months (Fig. 8b).
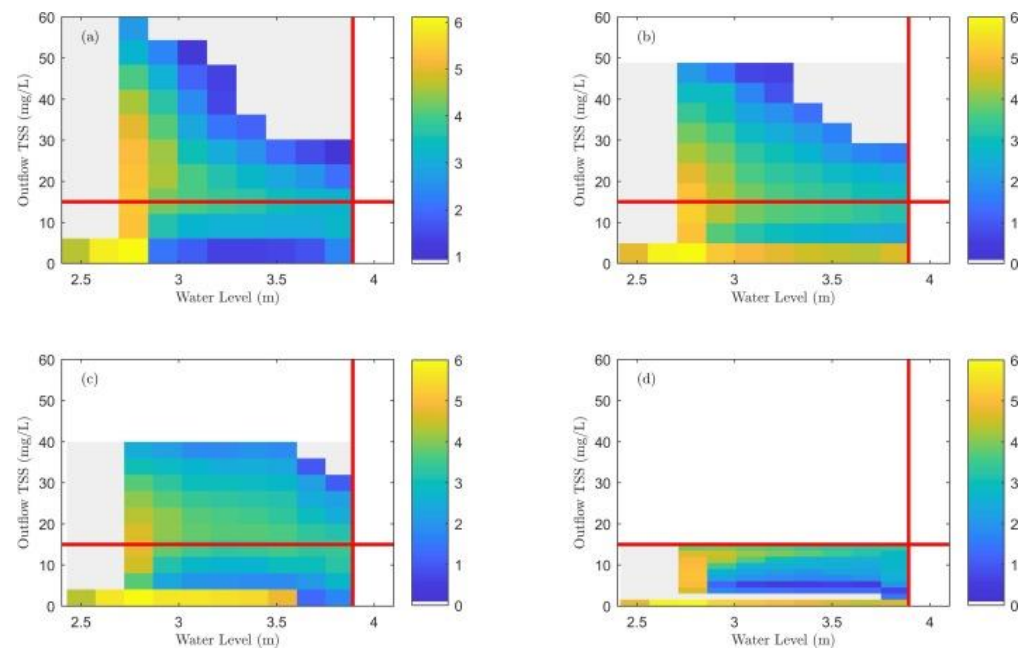

Fig. 7. Bivariate histogram plot of pond outflow TSS vs. water level for the month of June from EPA SWMM simulation. (a) Passive control, (b) detention control, (c) on/off control, (d) TSS control. The red line perpendicular to the $y$-axis is the limit state function for TSS failure and the red line perpendicular to $x$-axis is the limit state function for overflow failure.
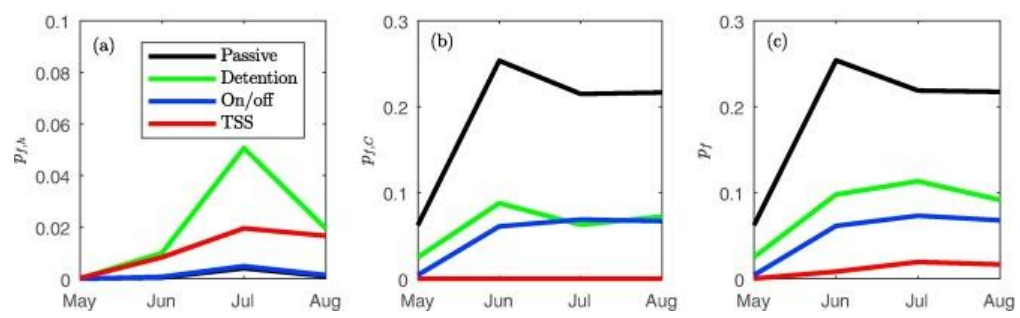

Fig. 8. Simulated failure probabilities for different controls for different simulation months: (a) water level failure, (b) TSS concentration failure, and (c) total system failure.

The water level and TSS concentration failure probabilities, $p_{f, h}$ and $p_{f, C}$, respectively, for each month are summarized in Fig. 8. The passive control had the lowest $p_{f, h}$ and the on/off control had slightly larger, but similar $p_{f, h}$ (Fig. 8a). In contrast, the detention and TSS controls had the highest $p_{f, h}$, with the largest $p_{f, h}$ simulated for detention control in July. The on/off control had the lowest $p_{f, h}$ of the three active controls. The passive control had the largest $p_{f, C}$, whereas the on/off and detention controls had similar, lower $p_{f, C}$ (Fig. 8b). For May and June, detention control $p_{f, C}$ was larger than on/off control $p_{f, C}$. In July and August, the $p_{f, C}$ was similar for detention and on/off control. Finally, the TSS control $p_{f, C}$ was zero.

With respect to pf, the relative performance of the four control scenarios did not depend on the month of analysis. The TSS control had the lowest and the passive control had the largest pf for all months (Fig. 8c). The detention control had the second largest and the on/off control had the second lowest pf. Across a gradient of increasing storm intensity and decreasing storm frequency (i.e., from May to 
August), pf increased for the TSS and on/off controls, while pf showed a maximum for the passive and detention controls. The performance of the passive and active controls therefore depended on the rainfall statistics for each month.

Table 2 shows the percent decrease in pf for each active control compared to the passive control. Detention control had the largest pf of all the active controls. The pf decreased by 59.6\%, 61.4\%, 48.2\% and, 57.8\% compared to the passive control for May, June, July and, August, respectively. For on/off control, the pf decreased by $93 \%, 75.8 \%, 66.5 \%$, and $68.7 \%$ compared to the passive control for each month, respectively. For the TSS control, the pf decreased by $99.5 \%, 96.7 \%, 91.1 \%$, and $92.3 \%$ for each month, respectively. Therefore, the detention control consistently performed worse than the TSS and on/off controls and the TSS control showed similar high performance across all months.

Table 2. Percent decrease (\%) in pf for active controls compared to passive control.

\begin{tabular}{|l|l|l|l|}
\hline Month & Detention & On/off & TSS \\
\hline May & 59.6 & 93 & 99.5 \\
\hline June & 61.4 & 75.8 & 96.7 \\
\hline July & 48.2 & 66.5 & 91.1 \\
\hline August & 57.8 & 68.7 & 92.3 \\
\hline
\end{tabular}

\subsection{Duration curve analysis}

Duration curves for daily peak water level, daily peak flow, daily sediment load, and daily peak TSS concentration are plotted in Fig. 9 for the month of June. The passive control resulted in the lowest water level duration curve (Fig. 9a). The detention and TSS controls increased the water level duration curve across all exceedance probabilities compared to passive control. The on/off control resulted in the largest daily peak water levels for low water levels with exceedance probabilities greater than $5 \%$. However, the TSS and detention control water level was greater than the on/off control water level for high water levels with exceedance probabilities less than $5 \%$.
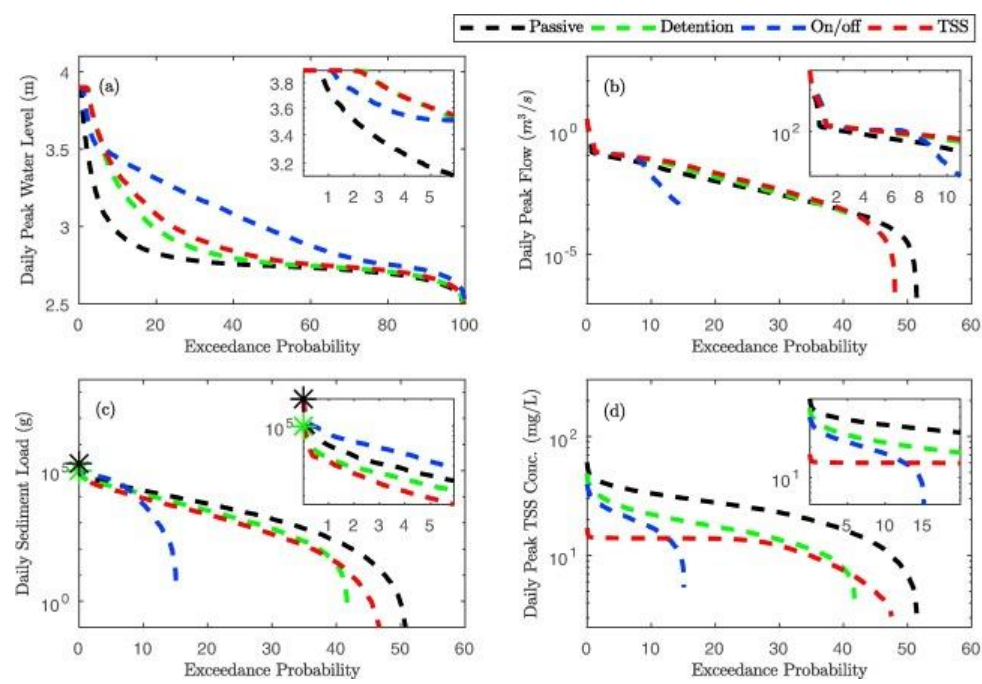

Fig. 9. Simulated duration curves for (a) daily peak water level, (b) daily peak flow, (c) daily peak sediment load, (d) daily peak concentration. 
Daily peak flow duration curves were similar across all four control scenarios (Fig. 9b). One exception to this result is that for the on/off control, the valve was closed approximately $80 \%$ of the time, and for the detention control, the valve was closed approximately $60 \%$ of the time. This was reflected in the corresponding flow duration curves.

Daily sediment load duration curves are plotted in Fig. 9c. The passive control resulted in the largest sediment load duration curve across all exceedance probabilities. The TSS control and detention control resulted in very similar daily sediment load duration curves. For high sediment loads with exceedance probabilities greater than $30 \%$, the TSS control decreased the daily sediment load relative to the detention control. The on/off control performed similar to the passive control for high sediment loads with exceedance probabilities less than $10 \%$ and decreased sediment loads with exceedance probabilities greater than $10 \%$.

Daily peak TSS concentration duration curves are plotted in Fig. 9d. All active controls decreased the daily peak TSS concentration for all exceedance probabilities relative to the passive control. The TSS control resulted in the lowest TSS concentration when the valve was open. The on/off control resulted in lower TSS concentration than detention and passive control when the valve was open and released zero TSS when the valve was closed $85 \%$ of the time. The detention control resulted in higher TSS concentration than the other active controls and had a similar valve open time to the TSS control.

\subsection{Sensitivity of active control performance to rainfall statistics}

The sensitivity of active control performance to the Modified BLRPM parameters is plotted in Fig. 10. The mean storm arrival frequency, $\lambda$, and the mean cell depth, $\mu_{x}$, were varied such that the mean expected value of daily rainfall remained constant, $\lambda \mu_{x} \mu_{c} \frac{v}{\alpha-1}$ (Islam et al., 1990). The $p_{f, h}$ decreased with $\lambda$ for passive, on/off, and detention controls (Fig. 10a). For TSS control, the $p_{f, h}$ shows a peak around $\lambda=0.025 \mathrm{~h}^{-1}$. The $p_{f, C}$ increased with $\lambda$ for the passive, on/off, and detention controls, whereas the $p_{f, C}$ for the TSS control was equal to zero for all values of $\lambda$ (Fig. 10b). The pf increases with $\lambda$ for passive, on/off, and detention controls, while it showed a peak for TSS control. This is because the pf for the TSS control was dominated by the $p_{f, h}$ which shows peak around $\lambda$ value of $0.025 \mathrm{~h}^{-1}$, whereas the $p_{f}$ for the other controls was dominated by the $p_{f, C}$.
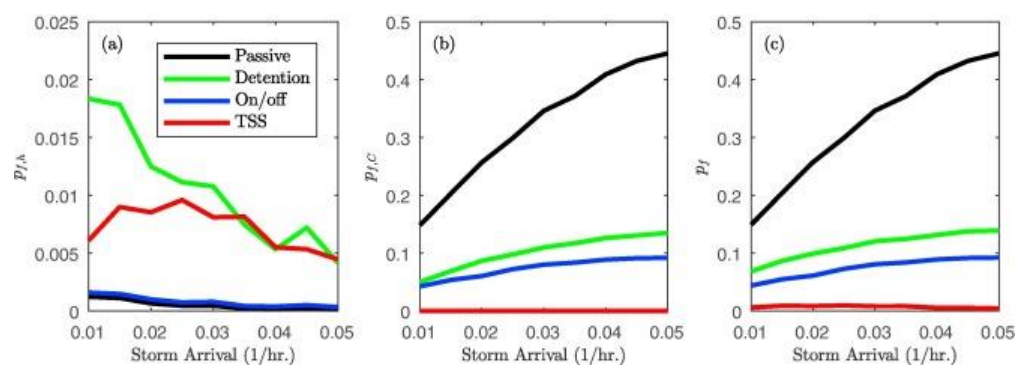

Fig. 10. (a) $p_{f, h}$, (b) $p_{f, C}$, (c) pf for passive, detention, on/off, and TSS control for different storm arrival rates. On the $x$-axis, the storm arrival rate, $\lambda$, is varied, while the average daily rainfall is maintained constant. 


\section{Discussion}

A continuous simulation, Monte Carlo approach was employed to evaluate the performance of several algorithms for real-time, active control of stormwater detention basin outflows. Active controls based on basin water level, detention time, and TSS concentration were compared to a baseline scenario with no outflow control (i.e., passive control). The active controls were compared within a simulation model that coupled hydrologic and pollutant dynamics in an urbanized watershed, forced by stochastic rainfall. This comparison provides insight into the attributes of "smart" stormwater systems (Mullapudi et al., 2017) and their sensitivity to rainfall-runoff and pollutant buildup-washoff dynamics.

Previous experimental and modeling studies demonstrated TSS removal efficiencies in stormwater detention basins ranging between 60 and 91\% (Shammaa et al., 2002, Chen and Adams,

2006, Middleton and Barrett, 2008, Gaborit et al., 2013, Carpenter et al., 2014, Muschalla et al., 2014). In the simulations presented here, the average TSS removal efficiencies across all simulation months were $64 \%, 87 \%, 77 \%$, and $95 \%$ for passive, detention, on/off, and TSS controls, respectively. Therefore, the TSS removal efficiency performance of our active controls improved on the passive control and was consistent with previous findings. The detention and TSS controls resulted in the largest TSS removal efficiencies.

Despite their similarity with respect to average TSS removal efficiency, the three active controls differed with respect to their performance during specific days. The detention and TSS control behaved similarly. The two were nearly identical for exceedance probabilities less than $40 \%$ for pond water level and peak daily flow. However, in the same exceedance probability range, the TSS control decreased the sediment load and peak TSS concentration more than the detention control. At lower exceedance probabilities of less than $2 \%$, the detention and TSS control behave similarly. The on/off control resulted in more sediment loads than any other controls for exceedance probabilities greater than $10 \%$. Therefore, the maximum TSS removal efficiency of the TSS control seems to result from its ability to reduce sediment loads under high probability, low sediment load events. These differences in sediment load may have implications for fluvial geomorphology of receiving streams (Poff et al., 1997). In addition to TSS load reduction, stormwater management systems may also be designed to control TSS concentrations in downstream receiving waters. Suspended sediment concentration is an important control of aquatic ecosystem function through its impact on light availability and transport of nutrients, metals, and other contaminants (Bilotta and Brazier, 2008). In general, all three active controls evaluated here reduced TSS concentrations compared to the passive scenario at exceedance probabilities less than $50 \%$. Throughout the entire range of exceedance probabilities, the TSS control resulted in the lowest suspended sediment concentration followed by on/off, detention, and passive control.

The model simulations demonstrated a trade-off between the $p_{f, h}$ and $p_{f, C}$ that varied across the active controls. All of the active controls increased the basin water level and, accordingly, the $p_{f, h}$. Basin water levels and $p_{f, h}$ scaled directly with the fraction of time the valve was closed for each active control, $90 \%, 80 \%$, and $40 \%$ for on/off, detention, and TSS control, respectively. Therefore, the TSS control not only captured the most sediment, but also minimally altered the hydrologic function of the stormwater basin from the baseline passive scenario. 
The detention control provided a detention time of $24 \mathrm{~h}$, resulting in $87 \%$ pollutant removal efficiency. On the other hand, the TSS control provided an average of $8.2 \mathrm{~h}$ of detention time with a removal efficiency of $95 \%$. The on/off control provided an average of $74 \mathrm{~h}$ of detention time, but the pollutant removal efficiency was only $77 \%$. Therefore, the TSS control provides the largest removal efficiency with the shortest detention time. This indicates that a longer detention time doesn't always lead to increased pollutant removal efficiency.

Rainfall characteristics were a critical determinant of both passive and active control performance. Under passive conditions, pf increased with the mean storm arrival frequency, $\lambda$, primarily driven by $p_{f, C}$. This pattern likely results from interaction between the rainfall-runoff and buildup-washoff processes. For climates characterized by low frequency, high intensity events, long inter-storm times allow watershed pollutant storage to saturate with minimal opportunity for stored pollutants to washoff into the stormwater basin. As storm frequency increases, buildup is maintained at a higher rate and washoff occurs more frequently, which we expect leads to a concomitant increase in $p_{f, C}$. Active control performance was most sensitive to rainfall characteristics for the detention and TSS control. Indeed, for months characterized by infrequent, high intensity storms (i.e., June, July, and August), $p_{f, h}$ and $p_{f, C}$ increased. When the total rainfall was held constant, $p_{f, C}$ also increased for frequent, low intensity events whereas $p_{f, h}$ decreased or showed a maximum with $\lambda$. Therefore, the variability in external climate forcing and internal interactions among system components are important to the overall effectiveness of real-time control of stormwater systems.

In this study, changes in climate parameters such as temperature or wind speed were not considered, while the simulated synthetic rainfall scenarios correspond to possible variability of rainfall frequency and intensity due to climate change (Kunkel et al., 2013). Across the spectrum of rainfall scenarios modeled here, the TSS control resulted in zero $p_{f, C}$ and the lowest and least variable system failure. Increased TSS load is expected due to climate change (He et al., 2010, Wilson and Weng, 2011, Sharma et al., 2016). Our results indicate the TSS control may be more adaptive to climate change by considering the concurrent impact of changes in rainfall-runoff and buildup-washoff processes on stormwater runoff water quality.

\section{Conclusion}

Active stormwater system controls driven by water quality information or detention time show promise to improve the water quality of stormwater basin outflows beyond traditional controls based on water level alone. On average, the TSS control reduces the system failure probability by $18.7 \%$ and $38.7 \%$ relative to the on/off and detention controls, respectively. The TSS and detention controls settle $18.9 \%$ and $11.4 \%$ more suspended solids relative to the on/off control. This is because the water quality and the detention controls provide a more direct measure of basin water quality as compared to water level measurements. The TSS control evaluated here closed the outflow valve only $40 \%$ of the time, because it was able to open the valve when the water quality reached the target level, thereby maintaining a high level of available storage in the pond. In cases where high cost or measurement uncertainty limits the opportunity for real-time water quality measurements, a detention time method can be implemented to achieve similar reductions in TSS concentration and loading. However, the 
performance of the detention time control was strongly influenced by the rainfall characteristics and in some cases, detention time control may therefore not be effective when compared to TSS control.

\section{Declaration of interests}

None.

\section{Acknowledgements}

The authors thank Dr. Ting Lin for comments on an earlier draft of this manuscript. SS, WMD, and AJP acknowledge support from the National Science Foundation Industry/University Cooperative Research Center on Water Equipment \& Policy located at the University of Wisconsin Milwaukee (IIP-1540032) and Marquette University (IIP- 711 1540010).

\section{References}

Alexander et al., 2006. L.V. Alexander, X. Zhang, T.C. Peterson, J. Caesar, B. Gleason, A.M.G. Klein Tank, M. Haylock, D. Collins, B. Trewin, F. Rahimzadeh, A. Tagipour, K. Rupa Kumar, J. Revadekar, G. Griffiths, L. Vincent, D.B. Stephenson, J. Burn, E. Aguilar, M. Brunet, M. Taylor, M . New, P. Zhai, M. Rusticucci, J.L. Vazquez-Aguirre. Global observed changes in daily climate extremes of temperature and precipitation. J. Geophys. Res. Atmos. (2006), 10.1029/2005JD006290

Alley, 1981. W.M. Alley. Estimation of impervious-area washoff parameters. Water Resour. Res., 17 (1981), pp. 1161-1166, 10.1029/WR017i004p01161

Angel et al., 2018.

J. Angel, C. Swanston, B.M. Boustead, K.C. Conlon, K.R. Hall, J.L. Jorns, K.E. Kunkel, M.C. Lemos, B. Lofgre n, T.A. Ontl, J. Posey, K. Stone, G.D.T. Takle. Midwest.

D.R. Reidmiller, C.W. Avery, D.R. Easterling, K.E. Kunkel, K.L.M. Lewis, T.K. Maycock, B.C. Stewart (Eds.), I mpacts, Risks, and Adaptation in the United States: Fourth National Climate Assessment, U.S. Global Change Research Program, Washington, DC (2018), pp. 872-940, 10.7930/NCA4.2018.CH21

Bilotta and Brazier, 2008. G.S. Bilotta, R.E. Brazier. Understanding the influence of suspended solids on water quality and aquatic biota. Water Res. (2008), 10.1016/j.watres.2008.03.018

Carpenter et al., 2014. J.F. Carpenter, B. Vallet, G. Pelletier, P. Lessard, P.A. Vanrolleghem. Pollutant removal efficiency of a retrofitted stormwater detention pond. Water Qual. Res. J. Canada, 49 (2014), pp. 124134, 10.2166/wqrjc.2013.020

Chen and Adams, 2006. J. Chen, B.J. Adams. Urban stormwater quality control analysis with detention ponds. Water Environ. Res., 78 (2006), pp. 744-753, 10.2175/106143005x72939

Colas et al., 2004. H. Colas, M. Pleau, J. Lamarre, G. Pelletier, P. Lavallée. Practical perspective on real-time control. Water Qual. Res. J. Canada, 39 (2004), pp. 466-478, 10.2166/wqrj.2004.058

Daly et al., 2012. E. Daly, A. Deletic, B.E. Hatt, T.D. Fletcher. Modelling of stormwater biofilters under random hydrologic variability: a case study of a car park at Monash University, Victoria (Australia). Hydrol. Process., 26 (2012), pp. 3416-3424, 10.1002/hyp.8397

Gaborit et al., 2016. E. Gaborit, F. Anctil, G. Pelletier, P.A. Vanrolleghem. Exploring forecast-based management strategies for stormwater detention ponds. Urban Water J., 13 (2016), pp. 841851, 10.1080/1573062X.2015.1057172

Gaborit et al., 2013. E. Gaborit, D. Muschalla, B. Vallet, P.A. Vanrolleghem, F. Anctil. Improving the performance of stormwater detention basins by real-time control using rainfall forecasts. Urban Water J., 10 (2013), pp. 230-246, 10.1080/1573062X.2012.726229

He et al., 2010. J. He, C. Valeo, A. Chu, N.F. Neumann. Characterizing physicochemical quality of storm-water runoff from an urban area in Calgary, Alberta. J. Environ. Eng., 136 (2010), pp. 1206$1217,10.1061 /$ (asce)ee.1943-7870.0000267 
Hoppe et al., 2011. H. Hoppe, S. Messmann, A. Giga, H. Gruening. A real-time control strategy for separation of highly polluted storm water based on UV-Vis online measurements - from theory to operation. Water Sci. Technol., 63 (2011), pp. 2287-2293, 10.2166/wst.2011.164

Islam et al., 1990. S. Islam, D. Entekhabi, R.L. Bras, I. Rodriguez-Iturbe. Parameter estimation and sensitivity analysis for the modified Bartlett-Lewis rectangular pulses model of rainfall. J. Geophys. Res., 95 (1990), pp. 2093-2100, 10.1029/JD095iD03p02093

Jacopin et al., 2001. C. Jacopin, E. Lucas, M. Desbordes, P. Bourgogne. Optimisation of operational management practices for the detention basins. Water Sci. Technol., 44 (2001), pp. 277-285

Khaliq and Cunnane, 1996. M.N. Khaliq, C. Cunnane. Modelling point rainfall occurrences with the modified Bartlett-Lewis Rectangular Pulses Model. J. Hydrol., 180 (1996), pp. 109-138, 10.1016/00221694(95)02894-3

Kunkel et al., 2013.

K.E. Kunkel, T.R. Karl, H. Brooks, J. Kossin, J.H. Lawrimore, D. Arndt, L. Bosart, D. Changnon, S.L. Cutter, N . Doesken, K. Emanuel, P.Y. Groisman, R.W. Katz, T. Knutson, J. O’brien, C.J. Paciorek, T.C. Peterson, K. Re dmond, D. Robinson, J. Trapp, R. Vose, S. Weaver, M. Wehner, K. Wolter, D. Wuebbles. Monitoring and understanding trends in extreme storms: state of knowledge. Bull. Am. Meteorol. Soc. (2013), 10.1175/BAMS-D-11-00262.1

Lacour et al., 2011. C. Lacour, C. Joannis, M. Schuetze, G. Chebbo. Efficiency of a turbidity-based, real-time control strategy applied to a retention tank: a simulation study. Water Sci. Technol., 64 (2011), pp. 1533-1539, 10.2166/wst.2011.545

Lacour and Schütze, 2011. C. Lacour, M. Schütze. Real-time control of sewer systems using turbidity measurements. NOVATECH 2016. 9th Int. Conf Plan. Technol. Sustain. Urban Water Manage. (2011), pp. 2628-2632, 10.2166/wst.2011.159

Leopold, 1968. L.B. Leopold. Hydrology for urban land planning: a guidebook on the hydrologic effects of urban land use. U.S. Geol. Surv. Circ. (1968), p. 554

Meyer et al., 2005. J.L. Meyer, M.J. Paul, W.K. Taulbee. Stream ecosystem function in urbanizing landscapes. J. North Am. Benthol. Soc. (2005), 10.1899/04-021.1

Middleton and Barrett, 2008. J.R. Middleton, M.E. Barrett. Water quality performance of a batch-type stormwater detention basin. Water Environ. Res., 80 (2008), pp. 172-178, 10.2175/106143007X220842

Miller and Hutchins, 2017. J.D. Miller, M. Hutchins. The impacts of urbanisation and climate change on urban flooding and urban water quality: a review of the evidence concerning the United Kingdom. J. Hydrol. Reg. Stud. (2017), 10.1016/j.ejrh.2017.06.006

Mullapudi et al., 2017. A. Mullapudi, B.P. Wong, B. Kerkez. Emerging investigators series: building a theory for smart stormwater systems. Environ. Sci. Water Res. Technol., 3 (2017), pp. 66-77, 10.1039/c6ew00211k

Muschalla et al., 2014. D. Muschalla, B. Vallet, F. Anctil, P. Lessard, G. Pelletier, P.A. Vanrolleghem. Ecohydraulicdriven real-time control of stormwater basins. J. Hydrol. (2014), 10.1016/j.jhydrol.2014.01.002

Parolari et al., 2018. A.J. Parolari, S. Pelrine, M.S. Bartlett. Stochastic water balance dynamics of passive and controlled stormwater basins. Adv. Water Resour. (2018), 10.1016/j.advwatres.2018.10.016

Pleau et al., 2005. M. Pleau, H. Colas, P. Lavallée, G. Pelletier, R. Bonin. Global optimal real-time control of the Quebec urban drainage system. Environ. Model. Softw., 20 (2005), pp. 401413, 10.1016/j.envsoft.2004.02.009

Poff et al., 1997. N.L. Poff, J.D. Allan, M.B. Bain, J.R. Karr, K.L. Prestegaard, B.D. Richter, R.E. Sparks, J. Stromberg. The natural flow regime: a paradigm for river conservation and restoration. Bioscience, 47 (1997), pp. 769-784

Rode et al., 2016.

M. Rode, A.J. Wade, M.J. Cohen, R.T. Hensley, M.J. Bowes, J.W. Kirchner, G.B. Arhonditsis, P. Jordan, B. K ronvang, S.J. Halliday, R.A. Skeffington, J.C. Rozemeijer, A.H. Aubert, K. Rinke, S. Jomaa. Sensors in the stream: the high-frequency wave of the present. Environ. Sci.

Technol. (2016), 10.1021/acs.est.6b02155 
Rodriguez-Iturbe et al., 1987. I. Rodriguez-Iturbe, D.R. Cox, V. Isham. Some models for rainfall based on stochastic point processes. Proc. R Soc. A Math. Phys. Eng. Sci., 410 (1987), pp. 269288, 10.1098/rspa.1987.0039

Rodriguez-Iturbe et al., 1988. I. Rodriguez-Iturbe, D.R. Cox, V. Isham. A point process model for rainfall: further developments. Proc. R Soc. A Math. Phys. Eng. Sci., 417 (1988), pp. 283-298, 10.1098/rspa.1988.0061

Rossman, 2015. L.A. Rossman. Storm Water Management Model User's Manual (2015), pp. 1-353

Schuëller and Stix, 1987. G.I. Schuëller, R. Stix. A critical appraisal of methods to determine failure probabilities. Struct. Saf., 4 (1987), pp. 293-309, 10.1016/0167-4730(87)90004-X

Shammaa et al., 2002. Y. Shammaa, D.Z. Zhu, L.L. Gyürék, C.W. Labatiuk. Effectiveness of dry ponds for stormwater total suspended solids removal. Can. J. Civ. Eng., 29 (2002), pp. 316-324, 10.1139/102-008

Sharma et al., 2016. A.K. Sharma, L. Vezzaro, H. Birch, K. Arnbjerg-Nielsen, P.S. Mikkelsen. Effect of climate change on stormwater runoff characteristics and treatment efficiencies of stormwater retention ponds: a case study from Denmark using TSS and $\mathrm{Cu}$ as indicator pollutants. Springerplus, 5 (2016), 10.1186/s40064-016-3103-7

Shinozuka, 1983. M. Shinozuka. Basic analysis of structural safety. J. Struct. Eng., 109 (1983), pp. 721740, 10.1061/(asce)0733-9445(1983) 109:3(721)

Smithers et al., 2002. J.C. Smithers, G.G.S. Pegram, R.E. Schulze. Design rainfall estimation in South Africa using Bartlett-Lewis rectangular pulse rainfall models. J. Hydrol., 258 (2002), pp. 83-99, 10.1016/S00221694(01)00571-6

Tik et al., 2015. S. Tik, T. Maruéjouls, P. Lessard, P.A. Vanrolleghem. Water quality-based control evaluation by means of an integrated urban wastewater model. Proc. 10th Int. Urban Drain. Model., Conf (2015), pp. 171-175

Walsh et al., 2005. C.J. Walsh, A.H. Roy, J.W. Feminella, P.D. Cottingham, P.M. Groffman, R.P. Morgan. The urban stream syndrome: current knowledge and the search for a cure. J. North Am. Benthol. Soc., 24 (3) (2005), pp. 706-723, 10.1899/04-028.1

Wang and Guo, 2019. J. Wang, Y. Guo. Stochastic analysis of storm water quality control detention ponds. J. Hydrol., 571 (2019), pp. 573-584, 10.1016/j.jhydrol.2019.02.001

Wilson and Weng, 2011. C.O. Wilson, Q. Weng. Simulating the impacts of future land use and climate changes on surface water quality in the Des Plaines River watershed, Chicago Metropolitan Statistical Area. Illinois. Sci. Total Environ., 409 (2011), pp. 4387-4405, 10.1016/j.scitotenv.2011.07.001

Wong and Kerkez, 2018. B.P. Wong, B. Kerkez. Real-time control of urban headwater catchments through linear feedback: performance, analysis, and site selection. Water Resour.

Res. (2018), 10.1029/2018WR022657 